\title{
Risk factors of cardiac insufficiency in children with multisystem inflammatory syndrome and COVID-19: A prospective cohort study
}

\author{
Nina Mól' , Anna Olchawa-Czech¹, Izabela Szymońska , Katarzyna Ptak¹, Katarzyna Konarska², \\ Sebastian Góreczny², Przemko Kwinta' ${ }^{1}$ \\ 'Department of Pediatrics, Jagiellonian University Medical College, Kraków, Poland \\ 2Department of Pediatric Cardiology, University Children's Hospital, Jagiellonian University Medical College, Kraków, Poland
}

\author{
Correspondence to: \\ Przemko Kwinta, MD, PhD \\ Department of Pediatrics, \\ Jagiellonian University \\ Medical College, \\ Wielicka 265, 30-663 Kraków, \\ Poland, \\ phone: +48 123339036 , \\ e-mail: \\ przemko.kwinta@uj.edu.pl \\ Copyright by the Author(s), 2021 \\ Kardiol Pol. 2021; \\ 79 (12): 1365-1367; \\ DOI: 10.33963/KP.a2021.0144 \\ Received: \\ September 1, 2021 \\ Revision accepted: \\ October 25, 2021 \\ Published online: \\ October 27, 2021
}

\section{INTRODUCTION}

SARS-CoV-2 infection was first described in late December 2019 in Wuhan, China [1]. In the beginning, it seemed that children displayed more benign symptoms or were even asymptomatic [2]. Nevertheless, 2-3 months later, an increasing number of pediatric patients with a new inflammatory condition that appeared to be geographically and temporally connected with COVID-19 were being admitted to hospitals at a high rate. The first reports of Multisystem Inflammatory Syndrome in Children (MIS-C) were published in May 2020 by Centers for Disease Control and Prevention [3]. Subsequent reports of cardiac involvement have also been published in other clinical presentations, including myocardial dysfunction, valvar regurgitation, pericarditis, coronary artery abnormalities, and arrhythmias [4]. This study aimed to analyze the clinical course of MIS-C with particular emphasis on the involvement of the circulatory system in a population of Polish children. Thus, we sought to identify risk factors of cardiac insufficiency in patients with MIS-C.

\section{METHODS}

\section{Study design}

A prospective, single-center study was conducted at the Department of Pediatrics, Jagiellonian University, Kraków, between December 1, 2020 and April 30, 2021. The study protocol was approved by the Jagiellonian University Medical College Ethical Committee (issue no. KBET/1072.6120.360.2020). Written and informed consent was obtained from the parents.

\section{Inclusion criteria}

Patients who fulfilled Centers for Disease Control and Prevention criteria for clinical diagnosis of MIS-C at admission were included in the study [5] (Supplementary material, Table S1).

\section{Study procedures}

On admission, nasopharyngeal swab tests for SARS-CoV-2 infection were performed by a polymerase chain reaction in all children. The levels of IgM and IgG antibodies against the viral spike glycoprotein using an Enzyme-Linked Immunosorbent Assay test were determined on admission. Moreover, serum concentrations of C-reactive protein, procalcitonin, troponin $\mathrm{T}$, ferritin, albumin, fibrinogen, D-dimer and N-terminal pro-brain natriuretic peptide were measured.

\section{Evaluation of the heart}

Echocardiography was performed in all children. The following echocardiographic parameters were calculated: (1) left ventricular ejection fraction based on Simpson's method; (2) fractional shortening based on M-Mode measurements. The presence of fluid in the pericardium, the presence of atrioventricular valve insufficiency, and the presence of coronary artery abnormalities were assessed.

\section{Study groups}

Based on the results of the cardiovascular evaluation, children were divided into 2 groups: 
Table 1. Comparison of the results of cardiological assessment between the studied groups

\begin{tabular}{|c|c|c|c|}
\hline & $\begin{array}{l}\text { Cardiac dysfunction } \\
\text { group }(n=20)\end{array}$ & $\begin{array}{c}\text { Non-cardiac dysfunction } \\
\text { group }(n=46)\end{array}$ & P-value \\
\hline Systolic blood pressure & $14(2-31)$ & $66(29-92)$ & $<0.001^{\mathrm{a}}$ \\
\hline Diastolic blood pressure & $14(9-40)$ & $68(28-92)$ & $0.002^{\mathrm{a}}$ \\
\hline FS & $27(23.6-32.1)$ & $32(30-34.4)$ & $0.003^{\mathrm{a}}$ \\
\hline EF & $52(48-55)$ & $61(59-65.2)$ & $<0.001^{\mathrm{a}}$ \\
\hline $\begin{array}{l}\text { Abnormal imaging of the coronary arteries } \\
\text { Aneurysms of coronary arteries } \\
\text { Hyperechogenicity of the coronary arteries }\end{array}$ & $\begin{array}{c}3(15) \\
1(5) \\
2(10)\end{array}$ & $\begin{array}{l}15(33) \\
3(6.5) \\
13(28)\end{array}$ & $\begin{array}{l}0.18^{b} \\
0.85^{b} \\
0.12^{b}\end{array}$ \\
\hline Pericardial effusion & $10(50)$ & $16(35)$ & $0.28^{\mathrm{b}}$ \\
\hline Mitral valve regurgitation & $10(50)$ & $20(43)$ & $0.79^{b}$ \\
\hline Tricuspid valve regurgitation & $14(70)$ & $26(57)$ & $0.41^{\mathrm{b}}$ \\
\hline Pericardial effusion $48-72$ hours after admission & $10(50)$ & $5(10.8)$ & $0.001^{\mathrm{b}}$ \\
\hline Mitral valve regurgitation $48-72$ hours after admission & $8(40)$ & $6(13)$ & $0.02^{\mathrm{b}}$ \\
\hline Tricuspid valve regurgitation $48-72$ hours after admission & $11(55)$ & $7(15)$ & $0.002^{\mathrm{b}}$ \\
\hline Abnormal imaging of the coronary arteries on discharge & 0 & $5(10.8)$ & $0.31^{\mathrm{b}}$ \\
\hline
\end{tabular}

a $P$-value for $U$ Mann-Whitney test; ${ }^{b} P$-value for Fisher exact test

Data are presented as number (\%) of patients or median (interquartile range [IQR]) unless otherwise indicated

Abbreviations: $E F$, ejection fraction; FS, fractional shortening

- A: MIS-C with significant cardiac dysfunction (CD) and/or shock (CD group);

- B: MIS-C without significant cardiac dysfunction or shock (the Non-CD group).

The following definitions of significant $C D$ and/or shock were used:

- Presence of hypotension as defined by systolic and/or diastolic blood pressure below the $5^{\text {th }}$ percentile for sex, age, and height [6]; or

- Decreased left ventricular ejection fraction below $55 \%$; or

- Decreased fractional shortening below $25 \%$.

\section{Statistical analysis}

The continuous variables were presented as median (interquartile range [IQR]) and compared between two groups using the Mann-Whitney $U$ test. Fisher's exact test was used to compare the categorical variables. A $P$-value of 0.05 , or less, was considered statistically significant. Statistical analyses were performed using IBM SPSS Statistics v. 27 software (Armonk, NY, USA).

\section{RESULTS AND DISCUSSION}

Sixty-six children with MIS-C were included in the study. The clinically significant CD was diagnosed in 20 (30\%) children. The most common reason for including the patient to the CD group was a reduced ejection fraction as identified by echocardiography, which was observed in $16(80 \%)$ patients. A reduction in shortening fraction and hypotension were noted in $12(60 \%)$ and $10(50 \%)$ patients from the CD group, respectively. The clinical characteristics and laboratory findings in the studied groups are presented in Supplementary material, Table S2 and S3.

The $\mathrm{CD}$ group was characterized by significantly higher inflammatory markers and granulocytosis with concomitant lymphopenia as well as significantly lower serum albumin and sodium concentrations. N-terminal pro-brain natriuretic peptide (NT-proBNP) values were significantly higher in the $\mathrm{CD}$ group.

Details of the cardiological assessment are presented in Table 1. Coronary artery abnormalities during hospitalization were observed in 18 (27\%) patients. The frequency of atrioventricular valve insufficiency and the presence of pericardial effusions were similar in both groups.

All patients received an intravenous infusion of immunoglobulins (IVIG) at a dose of $2 \mathrm{~g} / \mathrm{kg}$ body weight. Additionally, 64 children were treated with low to moderate doses of steroids.

In 4 patients who did not respond to IVIG or the low-to-moderate dose of glucocorticoids, IV pulse glucocorticoids ( $10-30 \mathrm{mg} / \mathrm{kg} /$ day) were given (3 CD group patients and 1 non-cardiac group patient). No patient needed to receive other immunomodulating agents.

Systemic hypotension was treated with intravenous fluids as a first step. CD was treated with an intravenous infusion of milrinone. In the cases with no response to treatment, children were transferred to the intensive care unit $(n=11)$ and treated with cardiac pressors.

All patients received antiplatelet therapy based on low doses of aspirin (3-5 mg/kg), and in cases of severe left ventricular dysfunction or increased D-dimer levels, they were administered an additional anticoagulation treatment (23 patients).

All children were discharged home in good general condition. The hospitalization time was longer in the $C D$ group than in the non-cardiac group (median [IQR]: 14 [13-16] days vs. 10 [9-12] days; $P<0.001$ ).

Our study described 66 previously healthy children who developed an inflammatory condition related to COVID-19. The median age of our cohort was 6.5 years, whereas in other studies patients were slightly older $[7,8]$. All patients presented a wide spectrum of symptoms, 
including fever, skin rash, conjunctivitis, vomiting, abdominal pain, diarrhea, and cardiac symptoms. A third of the patients developed heart dysfunction which required inotropic support. Our data contradict the data from the cohort described by Whittaker et al. [9], in which nearly half of the patients required cardiac support, and the data in the study by Ramcharan et al. [7], in which nearly $70 \%$ of MIS-C patients required inotropic support or vasopressors.

Davies et al. [10] found that "a third (28 [36\%] of 78) of patients were found to have coronary artery abnormalities on echocardiography during Pediatric Intensive Care Unit admission, 18 had evidence of aneurysms and 10 had coronary arteries that were characterized as unusually echogenic". In our study, we observed coronary artery abnormalities during hospitalization in $27 \%$ of patients with MIS-C. Additionally, these changes were more frequent in the non-CD group (33\% vs. 15\%). Although hyperechogenic coronary arteries were common on the 2D echocardiogram, all patients from the cardiac group had coronary artery dilation at the time of discharge from the hospital. However, it is worth noting that even the youngest children with MIS-C may develop extensive aneurysms of the coronary vessels [11].

Furthermore, we found no differences in the demographic data, fever duration, presence of skin rash, or gastrointestinal symptoms between CD and non-CD groups, and these observations were like previous findings $[8,10]$. Interestingly, we observed a strong positive correlation between conjunctivitis and the development of cardiac failure - in our cohort, $95 \%$ of children with heart insufficiency presented conjunctival hyperemia, whereas in the control group $77 \%$ developed such symptoms. These observations are contrary to previously published data, in which only $38 \%$ of patients with cardiac involvement suffered from conjunctivitis [9].

CD markers (troponin I, NT-proBNP), as well as D-dimers, were elevated in all patients. The elevation was statistically higher in patients with cardiac insufficiency, however, in our cohort we did not observe values at levels previously reported [7-9]. We noted decreased levels of albumin and sodium, which were statistically lower in the cardiac group and identical to other described cohorts [7-9]. We can presume that patients with serum levels of albumin over $35 \mathrm{~g} / \mathrm{l}$ and NT-proBNP levels below $1000 \mathrm{pg} / \mathrm{ml}$ were at low risk of developing cardiac insufficiency. Based on the laboratory tests, we can exclude severe courses of MIS-C with heart involvement in only $20 \%$ of patients. However, if cardiac markers and/or indicators of inflammation are increased, we may not be able to identify children who develop significant heart dysfunction.

Transferring patients with MIS-C and significantly abnormal laboratory values to the hospital with a higher level of care should be considered. All patients with MIS-C should be examined by a pediatric cardiologist upon admission to the hospital. We recommend a close follow-up for all patients diagnosed with MIS-C.

\section{Supplementary material}

Supplementary material is available at https://journals. viamedica.pl/kardiologia_polska.

\section{Article information}

Conflict of interest: None declared.

Open access: This article is available in open access under Creative Common Attribution-Non-Commercial-No Derivatives 4.0 International (CC BY-NC-ND 4.0) license, allowing to download articles and share them with others as long as they credit the authors and the publisher, but without permission to change them in any way or use them commercially. For commercial use, please contact the journal office at kardiologiapolska@ptkardio.pl.

How to cite: Mól N, Olchawa-Czech A, Szymońska I, et al. Risk factors of cardiac insufficiency in children with multisystem inflammatory syndrome and COVID-19: A prospective cohort study. Kardiol Pol. 2021; 79(12): 1365-1367, doi: 10.33963/KP.a2021.0144.

\section{REFERENCES}

1. Zhu Na, Zhang D, Wang W, et al. China Novel Coronavirus Investigating and Research Team. A novel coronavirus from patients with pneumonia in China, 2019. N Engl J Med. 2020; 382(8): 727-733, doi: 10.1056/NEJMoa2001017, indexed in Pubmed: 31978945.

2. Wu Z, McGoogan JM. Characteristics of and important lessons from the coronavirus disease 2019 (COVID-19) outbreak in China: summary of a report of 72314 cases from the Chinese Center for Disease Control and Prevention. JAMA. 2020; 323(13): 1239-1242, doi: 10.1001/jama.2020.2648, indexed in Pubmed: 32091533.

3. Centers for Disease Control and Prevention. Coronavirus disease 2019 in children - United States, February 12-April 2, 2020. Available online: www. cdc.gov/mmwr/volumes/69/wr/mm6914e4.htm (Accessed: May 16, 2020).

4. White M, Tiesman B, Handforth J, et al. Evelina PIMS TS working group. Paediatric inflammatory multisystem syndrome temporally associated with SARS-CoV-2 (PIMS-TS): the Evelina Experience. Arch Dis Child. 2020; 105(11): 1025-1027, doi: 10.1136/archdischild-2020-319554, indexed in Pubmed: 32912866.

5. Henderson LA, Canna SW, Friedman KG, et al. American College of Rheumatology Clinical Guidance for Multisystem Inflammatory Syndrome in Children Associated with SARS-CoV-2 and Hyperinflammation in Pediatric COVID-19: version 1. Arthritis Rheumatol. 2020; 72(11): 1791-1805, doi: 10.1002/art.41454, indexed in Pubmed: 32705809.

6. National High Blood Pressure Education Program Working Group on High Blood Pressure in Children and Adolescents. The fourth report on the diagnosis, evaluation, and treatment of high blood pressure in children and adolescents. Pediatrics. 2004; 114(2 Suppl $4^{\text {th }}$ Report): 555-576, doi: 10.1542/peds.114.2.s2.555, indexed in Pubmed: 15286277.

7. Ramcharan T, Nolan O, Lai C, et al. Paediatric Inflammatory Multisystem Syndrome:Temporally Associated with SARS-CoV-2 (PIMS-TS): cardiac features, management and short-term outcomes at a UK Tertiary Paediatric Hospital. Pediatr Cardiol. 2020; 41(7): 1391-1401, doi: 10.1007/s00246020-02391-2, indexed in Pubmed: 32529358.

8. Belhadjer Z, Méot M, Bajolle F, et al. Acute heart failure in multisystem inflammatory syndrome in children in the context of global SARSCoV-2 pandemic. Circulation. 2020; 142(5): 429-436, doi: 10.1161/CIRCULATIONAHA.120.048360, indexed in Pubmed: 32418446.

9. Whittaker E, Bamford A, Kenny J, et al. PIMS-TS Study Group and EUCLIDS and PERFORM Consortia. Clinical characteristics of 58 children with a pediatric inflammatory multisystem syndrome temporally associated with SARS-CoV-2. JAMA. 2020; 324(3):259-269, doi: 10.1001/jama.2020.10369, indexed in Pubmed: 32511692.

10. Davies $P$, Evans $C$, Kanthimathinathan $H K$, et al. Intensive care admissions of children with paediatric inflammatory multisystem syndrome temporally associated with SARS-CoV-2 (PIMS-TS) in the UK: a multicentre observational study. Lancet Child Adolesc Health. 2020; 4(9): 669-677, doi: 10.1016/S2352-4642(20)30215-7, indexed in Pubmed: 32653054.

11. Tracewski P, Ludwikowska KM, Szenborn L, et al. The first case of pediatric inflammatory multisystem syndrome temporally associated with SARS-CoV-2 infection (PIMS-TS) in Poland, complicated by giant coronary artery aneurysms. Kardiol Pol. 2020; 78(10): 1064-1065, doi: 10.33963/KP.15623, indexed in Pubmed: 32988176 